\title{
The burden of healthcare-associated infection in Ethiopia: a systematic review and meta-analysis
}

\author{
Abebaw Yeshambel Alemu ${ }^{1 *}$ (D) Aklilu Endalamaw² and Wubet Alebachew Bayih ${ }^{1}$
}

\begin{abstract}
Background: Different primary studies in Ethiopia showed the burden of nosocomial infection across geographical setting and variant period. However, the national level of burden and types of healthcare-associated infections were unknown. Hence, this systematic review and meta-analysis estimated the overall nationwide burden and types of healthcare-associated infections in Ethiopia.

Methods: We searched PubMed, Science Direct, Google Scholar, African Journal Online, and Addis Ababa University repository by date April 7, 2020. To assess publication bias, Egger's test regression analysis was applied. Weightinverse random-effect model meta-analysis was used. Subgroup analysis was conducted based on ward type, study region, study design, sample size and diagnostic method, ward type, and study participants.

Results: A total of 18 studies with 13,821 patients participated in the overall prevalence estimation. The pooled prevalence of healthcare-associated infection was 16.96\% (95\% Cl 14.10-19.82). Specifically, surgical site infection (39.66\%), urinary tract infection (27.69\%), bloodstream infection (19.9\%), dual infections (SSI and UTI) (14.01\%), and respiratory tract (13.51\%) were the commonest types of healthcare-associated infection. In subgroup analysis, the highest overall prevalence was observed as surgical, gynecology, and obstetrics ward (22.42\%).

Conclusions: The national prevalence of healthcare-associated infection remains high. The most common type of HCAI was surgical site infection, followed by urinary tract infection, bloodstream infection, SSI and UTI, and respiratory tract infection. The overall prevalence was highest in surgical, gynecology, and obstetrics ward. Hence, infection prevention and control should be a priority agenda in healthcare with due emphasis for surgical patients.
\end{abstract}

Keywords: Burden, Healthcare-associated infection, Meta-analysis, Ethiopia

\section{Background}

Healthcare-associated infection (HCAI) is a preventable infection that a patient can encounter in a healthcare facility while receiving medical care [1,2]. It occurs after $48 \mathrm{~h}$ of hospital admission, up to 3 days after discharge, or up to 30 days after the operation when someone was admitted for reasons other than infection [2]. Surgical site infection (SSI), urinary tract infection (UTI), bloodstream infection (BSI), and pneumonia or respiratory

\footnotetext{
* Correspondence: yeshambelabebaw@gmail.com

'Department of Paediatrics and Child Health Nursing, College of Health

Sciences, Debre Tabor University, Debre Tabor, Ethiopia

Full list of author information is available at the end of the article
}

tract infection (RTI) were the commonest types of HCAI elsewhere [1].

According to the World Health Organization (WHO) 2019 HCAI fact sheet report, a hundred million patients were affected each year globally. This report added that the point prevalence of HCAI was estimated in the ranges between $3.5-12 \%$ and $5.7-19.1 \%$ in developed and low- and middle-income countries, respectively [3]. Nosocomial infection (NI) was found between 1.6 and $28.7 \%$ in Sub-Saharan Africa [4]. Specifically, the overall prevalence of HCAI was found in Botswana (13.4\%) [5] and South Africa (8\%) [6]. Regarding types of HCAI, a meta-analysis showed that RTI, UTI, SSI, and BSI from

(c) The Author(s). 2020 Open Access This article is licensed under a Creative Commons Attribution 4.0 International License, which permits use, sharing, adaptation, distribution and reproduction in any medium or format, as long as you give appropriate credit to the original author(s) and the source, provide a link to the Creative Commons licence, and indicate if changes were made. The images or other third party material in this article are included in the article's Creative Commons licence, unless indicated otherwise in a credit line to the material. If material is not included in the article's Creative Commons licence and your intended use is not permitted by statutory regulation or exceeds the permitted use, you will need to obtain permission directly from the copyright holder. To view a copy of this licence, visit http://creativecommons.org/licenses/by/4.0/. 
highest to lowest magnitude in order were found worldwide, but SSI (51.1\%) was the leading in Africa [7]. Unlikely, nosocomial UTI was the utmost (35\%) in Morocco Rabat hospitals [8].

Healthcare infections increase morbidity, mortality, long-term disability [9], hospital stay [10], microbial resistance to antibiotics [11], and healthcare costs for patients and their families [12]. Besides, it upsurges the financial burden on the healthcare system [9]. Hence, "clean care the safer care" program has been launched since 2004 with the WHO patient safety directive, which was aimed to reduce HCAI through improving hand hygiene practice at the center of achieving its aim [13]. Similarly, infection prevention and control guideline was developed for health facilities [14], and infection prevention and control policy recommendations initiated by WHO has been implemented in Ethiopia. Yet, HCAI remains the global public health problem elsewhere.

In the Ethiopian setting, different studies had been conducted to find the overall prevalence of HCAI and its type. The overall prevalence of HCAI was found in the ranges of 9 to $35.8 \%$ [15-18]. Concerning types of HCAI, SSI (13.5 to $52 \%)[15,17,18]$, RTI (5 to $19 \%$ ) [12, 17], UTI ( 9.5 to $48 \%)[16,18,19]$, and BSI (4.3 to $46.6 \%)$ $[20,21]$ predominated in the country. However, all of the studies showed great variation across geographical setting and variant period. This discrepancy between studies makes it difficult to represent the national prevalence. Having national representative data is real to underpin effective prevention and control strategies. Thus, a need to have a pooled estimation of HCAI was necessitated at the country level. Therefore, this systematic review and meta-analysis aimed to estimate the overall pooled prevalence of HCAI and its types in Ethiopia.

\section{Methods and materials Reporting}

The results of this review were reported based on the Preferred Reporting Items for Systematic Review and Meta-analysis (PRISMA) statement guideline [22] (Additional file 1 research checklist), and it is registered in the PROSPERO database:(PROSPERO ID CRD42020183158).

\section{Search strategy and information source}

PubMed, Science Direct, Google Scholar, African Journal Online, and Addis Ababa University repository were searched. The core search terms and phrases were "prevalence", "incidence", "epidemiology", "proportion", "magnitude", "burden", "healthcare-associated infection", "healthcare-acquired infection", and "nosocomial infection", "hospital acquired infection", "surgical site infection", "urinary tract infection", "respiratory tract infection", "pneumonia", "ventilator associated pneumonia", "bloodstream infection", "central-line associated blood stream infection", "skin and soft tissue infection", and "Ethiopia". The search strategies were developed using different Boolean operators. Notably, to fit advanced PubMed database, the following search strategy was applied on April 7, 2020: [(prevalence[MeSH Terms]) OR incidence[MeSH Terms]) OR proportion[MeSH Terms]) OR epidemiology[MeSH Terms]) OR magnitude[MeSH Terms]) OR burden[MeSH Terms]) AND healthcare-associated infection [MeSH Terms]) OR nosocomial infection [MeSH Terms]) OR hospital acquired infection[MeSH Terms]) OR healthcare-acquired infection[MeSH Terms]) OR healthcare infection[MeSH Terms]) OR surgical site infection[MeSH Terms]) OR urinary tract infection[$\mathrm{MeSH}$ Terms]) OR respiratory tract infection[MeSH Terms]) OR pneumonia[MeSH Terms]) OR ventilator associated pneumonia[MeSH Terms]) OR bloodstream infection[MeSH Terms]) OR central-line associated blood stream infection[MeSH Terms]) OR skin and soft tissue infection[MeSH Terms]) AND (Ethiopia)].

\section{Study selection}

Retrieved studies were exported to the Endnote version 8 (Thomson Reuters, London) reference manager software to remove duplicate studies. Two independent reviewers screened the title and abstract. The disagreement was handled based on established article selection criteria. Two independent authors conducted the abstract and full-text review.

\section{Eligibility criteria Inclusion criteria}

Included studies were articles that reported the prevalence in general and/or at least one type of healthcareassociated infection. It also included studies published in English and studies conducted only in Ethiopia.

\section{Exclusion criteria}

Articles without full-text available and qualitative studies were excluded. Likewise, reviews, commentaries, consultants' corners, letters, and conference abstracts were not considered.

\section{Quality assessment}

We used Joanna Briggs Institute (JBI) quality appraisal criteria [23]. The tool consists of nine major items. The first item is appropriate to the sample frame. The second is the appropriate sampling technique. The third is the adequacy of the sample size. The fourth is a description of the study subjects and settings. The fifth is enough coverage of data analysis. The sixth is the validity of the method for identification of the condition. The seventh 
item is a standard and reliable measurement for all participants. The eighth is the appropriateness of statistical analysis. And the last item is adequacy and management of response rate. Studies were considered low-risk when it would fit 5 or above quality assessment checklists. Two independent authors appraised the quality of studies. The disagreement was resolved by the interference of a third reviewer.

\section{Data extraction}

Two authors extracted data using the standardized format. The name of the first author and year, study region, study design, ward type, diagnostic method(s), sample size, the prevalence for overall, and types of HCAI were extracted. Whenever variations are observed, the phase was repeated. If discrepancies between data extractors continued, the third reviewer was involved.

\section{Outcome measurement}

HCAI was considered, when reported as infection(s) acquired while receiving medical care based on culture confirmation [21, 24-27] or clinical and laboratory methods [10, 12, 15-20, 28-32]. Types of HCAI were any one or more of the following: SSI, UTI, BSI, RTI, or any other reported as healthcare-associated infection by included studies.

\section{Statistical analysis}

The required data were collected using a Microsoft Excel 2013 workbook. Then, the STATA version 11 statistical software was used for meta-analysis. Publication bias was objectively checked using Egger's regression test analysis [33]. Heterogeneity of studies was quantified using the I-squared statistic, in which 25,50 , and $75 \%$ represented low, moderate, and high heterogeneity, respectively [34]. Pooled analysis was conducted using a weighted inverse variance random-effects model [35]. Subgroup analysis was done by the region, study design, diagnostic method, and sample size. Besides, subgroup analysis was done based on ward type and study participants to overcome the inflation of the pooled effect from the inclusion of studies done across various wards and study participants with the age difference. Sensitivity analysis was employed to see the effect of a single study on the overall estimation.

\section{Results}

\section{Literature search}

The search strategy retrieved 1440 articles from PubMed, 398 from Science Direct, 3 from African Journal Online, 79 from Google Scholar, and 3 from Addis Ababa University repository. After duplication was removed, 1882 remained. Eighty studies were screened for full-text review. Finally, 18 studies were used for meta-analysis (Fig. 1).

\section{Characteristics of included studies}

Six studies were found in Addis Ababa [10, 12, 15, 27, 28, 32], five studies in Amhara region [16, 17, 24, 31, $36]$, five studies in Oromia [18-20, 25, 26], a study both in Addis Ababa and Southern Nations, Nationalities, and People's Region (SNNPR) [29], one each in Tigray [30] and SNNPR [21]. Nine studies were done across all age groups. Eight studies were done on the adult population, and one study was done on pediatric patients. Fourteen studies used clinical and laboratory methods to diagnosis HCAI while the remaining were culture-confirmed. Four studies were conducted by using cohort study design and fourteen were cross-sectional. Only six studies included > 1000 sample size. The studies included in this systematic review and meta-analysis had no considerable risk. Therefore, all the studies were considered $[10,12$, 15-21, 24-32] (Table 1).

Eleven of the studies have reported types of HCAI [10, 12, 15-18, 20, 21, 26, 28, 32] (Additional file 2). We assessed studies with JBI quality appraisal checklists. Based on this, none of the included studies was of poor quality status.

\section{Meta-analysis}

\section{The burden of healthcare-associated infection}

The absence of publication bias was assessed with Egger's regression test analysis $(p=0.456)$, which showed no publication bias.

The pooled prevalence of healthcare-associated infection estimated from 18 studies [10, 12, 15-21, 24-32] was $16.94 \%$ (95\% confidence interval (CI) 14.06-19.81) (Fig. 2).

Types of HCAI were estimated from the pooled effect of eleven studies [10, 12, 15-18, 20, 21, 26, 28, 32]. Accordingly, SSI (39.66\%) was the most prevalent type of HCAI, followed by UTI $(26.79 \%)$ and BSI (19.90\%) estimated from six studies $[15,17,18,20,21,26]$. Besides, six studies $[12,17,18,21,26,32]$ showed the prevalence of RTI (13.51\%). Moreover, the dual infections of SSI and UTI estimated from two studies $[18,20]$ was $14.01 \%$ (Fig. 3).

\section{Subgroup analysis}

Subgroup analysis was done based on the study region, study design, diagnostic method and sample size, ward type, and study participant. Based on the pooled effect of two or more studies, HCAI estimated from six studies $[10,12,15,27,28,32]$ was found to be the highest in Addis Ababa (18.37\%). Thirteen cross-sectional studies $[10,15-17,20,21,24-26,28,30-32]$ found $18.52 \%$ HCAI rate in Ethiopia. Thirteen studies [10, 12, 15-20, 28-32] showed HCAI diagnosed by both clinical and 


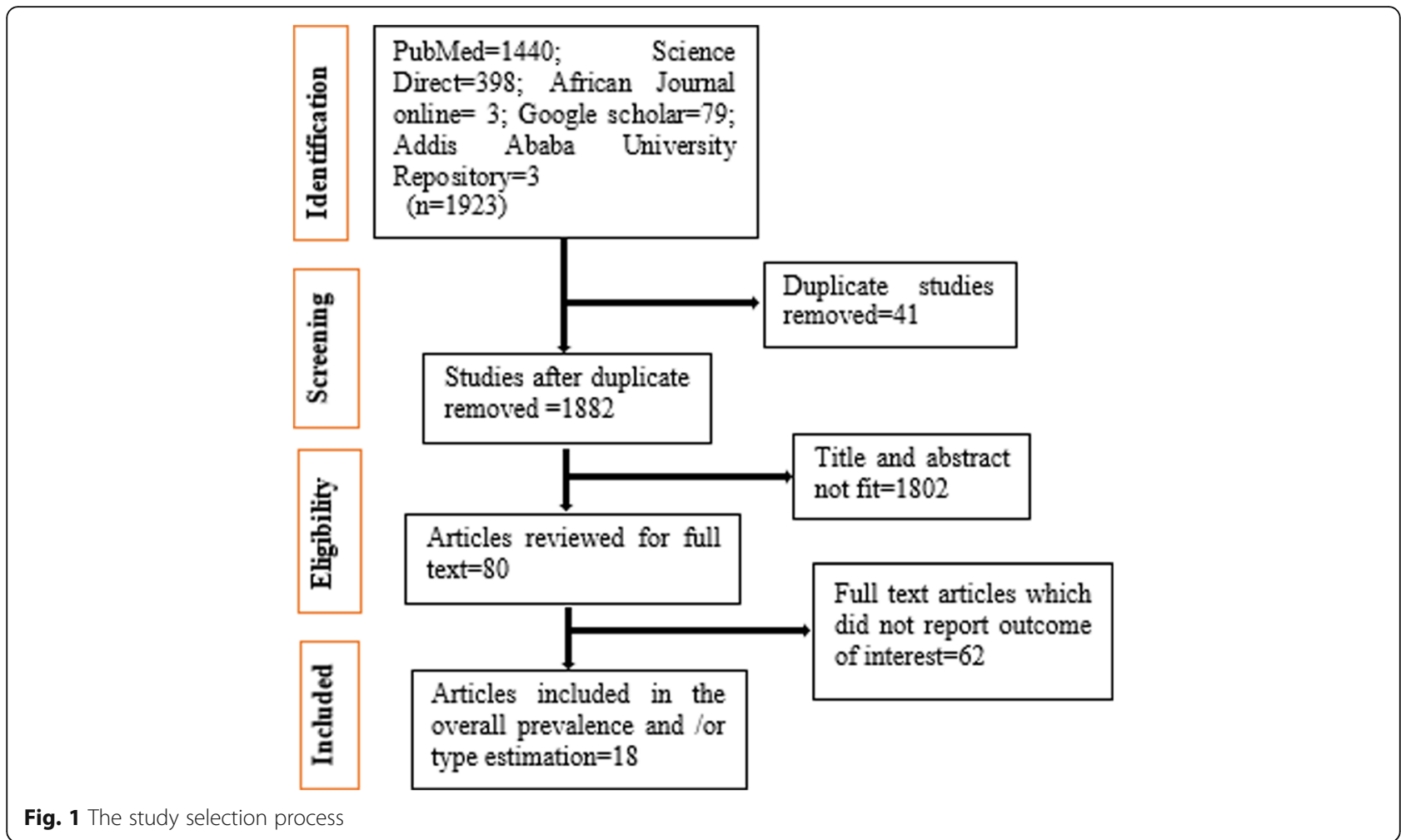

Table 1 Characteristics and quality status of the studies in the meta-analysis of HCAl

\begin{tabular}{|c|c|c|c|c|c|}
\hline First author year & Study region & Study design & Sample size & Prevalence & Quality status \\
\hline Gedebou et al. 1987 [28] & Addis Ababa & Cross sectional & 2506 & 13.40 & Low risk \\
\hline Gedebou et al. 1988 [10] & Addis Ababa & Cross sectional & 700 & 17.00 & Low risk \\
\hline Habte-Gabr et al. 1988 [12] & Addis Ababa & Cohort & 1006 & 16.40 & Low risk \\
\hline Berhe et al. 2001 [29] & Addis Ababa and SNNPR & Cohort & 247 & 5.90 & Low risk \\
\hline Woldesenbet 2018 [27] & Addis Ababa & Cohort & 435 & 8.5 & Low risk \\
\hline Tesfahun et al. 2009 [30] & Tigray region & Cross sectional & 246 & 27.60 & Low risk \\
\hline Endalafer et al. 2011 [15] & Addis Ababa & Cross sectional & 215 & 35.80 & Low risk \\
\hline Melaku et al. 2012 [16] & Amhara region & Cross sectional & 1383 & 17.80 & Low risk \\
\hline Melaku et al. 2012 [31] & Amhara region & Cross sectional & 1254 & 9.40 & Low risk \\
\hline Mulu et al. 2013 [24] & Amhara region & Cross sectional & 294 & 10.90 & Low risk \\
\hline Sahile et al. 2016 [20] & Oromia region & Cross sectional & 500 & 35 & Low risk \\
\hline Yallew et al. 2016 [17] & Amhara region & Cross sectional & 908 & 14.90 & Low risk \\
\hline Tolera et al. 2018 [26] & Oromia region & Cross sectional & 394 & 6.90 & Low risk \\
\hline Gashaw et al. 2018 [25] & Oromia region & Cross sectional & 1015 & 11.60 & Low risk \\
\hline Ali et al. 2018 [18] & Oromia region & Cohort & 1069 & 19.40 & Low risk \\
\hline Alemayehu et al. 2019 [21] & SNNPR & Cross sectional & 939 & 21.40 & Low risk \\
\hline Gebremeskel et al. 2018 [32] & Addis Ababa & Cross sectional & 410 & 19.80 & Low risk \\
\hline Zewdu et al. 2017 [19] & Oromia region & Cohort & 300 & 14.00 & Low risk \\
\hline
\end{tabular}




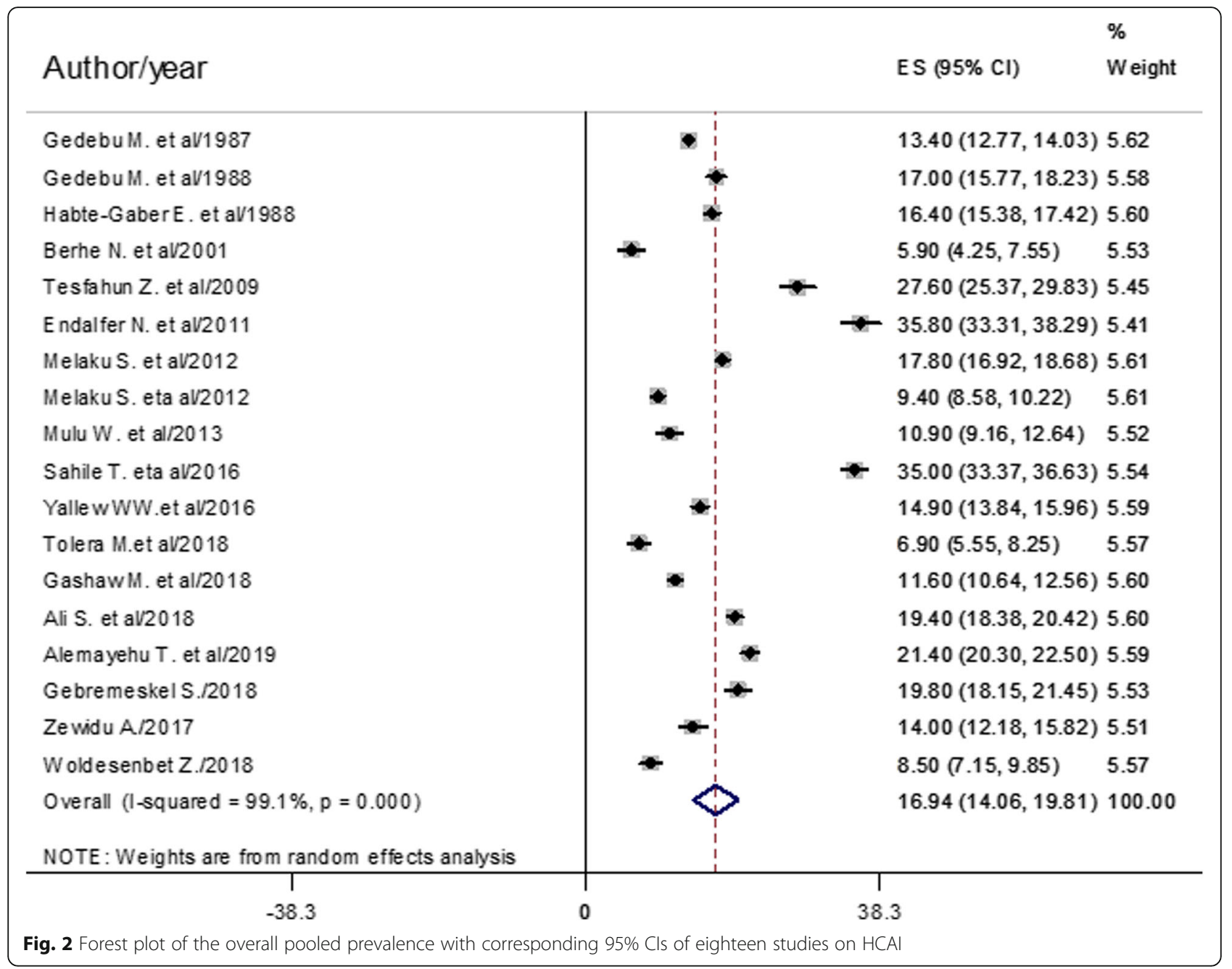

laboratory methods was $18.89 \%$. From the pooled effect of twelve studies [10,15, 17, 19-21, 24, 26, 27, 29, 30, 32] using study sample < 1000, HCAI was $18.11 \%$ (Table 2). The subgroup analysis was also done based on ward type. The highest prevalence of HCAI estimated from four studies $[16,20,30,31]$ was $22.42 \%$ in surgical, gynecology, and obstetrics ward, followed by the surgical ward (20.98\%) estimated from three studies [12, 15, 24] (Fig. 4).

Based on the subgroup analysis of study participants, the pooled prevalence of HCAI estimated from seven studies $[10,15,16,20,28,30,31]$ was $22.21 \%$ among the adult population (Fig. 5).

\section{Sensitivity analysis}

Endalafer et al. [15] and Sahile et al. [20] had shown an impact on the overall estimation of the meta-analysis result (Fig. 6).

\section{Discussion}

The Sustainable Development Goal (SDG) goal-3 is implemented to ensure access to quality essential healthcare services in every country [37]. However, HCAI confronts quality in healthcare systems that fail to build strong principles to reduce the risks and spread of nosocomial infection [38]. Thus, HCAI has been continued as preventable causes of morbidity, mortality, and spending health system cost.

This meta-analysis estimated the country level overall pooled prevalence of healthcare-associated infection and types in Ethiopia. Accordingly, the overall pooled prevalence of HCAI was 16.94\% (95\% CI 14.06-19.81) (Fig. 2). This result was higher than studies done in China (3.12\%) [39], Morocco (10.3\%) [8], Botswana (13.54\%) [5], and South Africa (7.67\%) [6]. The possible reasons for high prevalence in this study might be very low hand hygiene practice, low adherence to infection prevention practice, low level of job satisfaction, morally distressed nurses, resource constraints, low implementation of the nursing process, and less attention given to healthcareassociated infection.

Keeping hand hygiene before patient contact is vital to prevent NI. However, only $7 \%$ of physicians working at 


\begin{tabular}{|c|c|c|c|}
\hline Author/year & & $\mathrm{ES}(95 \% \mathrm{Cl})$ & $\begin{array}{l}\% \\
\text { Weight }\end{array}$ \\
\hline $\begin{array}{l}\text { Surgical site infection } \\
\text { Gedebu M. et aV1987 } \\
\text { Gedebu M. et aV1988 } \\
\text { Habte-Gabr E. et aV1988 } \\
\text { Melaku. et aV2012 } \\
\text { Sahile T. eta aV2016 } \\
\text { Yallew WW. eta aV2016 } \\
\text { Tolera M.et aV2018 } \\
\text { Alemayehu T. et aV2019 } \\
\text { Gebremeskel S. et aV2018 } \\
\text { Endalfer N. et aV2011 } \\
\text { Ali S. et aV2018 } \\
\text { Subtotal (l-squared }=99.1 \%, p=0.000 \text { ) }\end{array}$ & $\underset{+\infty}{+\infty}+$ & $\begin{array}{l}49.00(48.92,51.08) \\
47.00(43.55,50.45) \\
58.80(55.78,61.82) \\
45.60(43.21,47.99) \\
47.10(42.59,51.61) \\
51.10(47.83,54.37) \\
31.50(26.64,38.38) \\
18.20(14.69,21.71) \\
24.70(20.86,28.54) \\
49.40(45.07,53.73) \\
13.85(11.60,16.10) \\
39.88(30.00,49.32)\end{array}$ & $\begin{array}{l}9.16 \\
9.10 \\
9.12 \\
9.15 \\
9.02 \\
9.11 \\
8.99 \\
9.09 \\
9.07 \\
9.03 \\
9.16 \\
100.00\end{array}$ \\
\hline $\begin{array}{l}\text { Urinary tract infection } \\
\text { Gedebu M. et aV1987 } \\
\text { Gedebu M. et aV1988 } \\
\text { Habte-Gaber E. et aV1988 } \\
\text { Melaku. et aV2012 } \\
\text { Sahile T. eta aV2016 } \\
\text { Yallew WW. eta aV2016 } \\
\text { Tolera M.et aV2018 } \\
\text { Alemayehu T. et aV2019 } \\
\text { Gebremeskel S. et aV2018 } \\
\text { Endalfer N. et aV2011 } \\
\text { Ali S. et aV2018 } \\
\text { Subtotal (l-squared }=98.9 \%, p=0.000 \text { ) }\end{array}$ & $+\underset{+\infty}{+\infty}+$ & $\begin{array}{l}25.00(23.12,28.88) \\
15.00(12.08,17.92) \\
26.10(23.40,28.80) \\
48.00(45.59,50.41) \\
30.00(25.75,34.25) \\
6.70(4.39,9.01) \\
20.40(15.83,24.97) \\
22.70(19.07,28.33) \\
24.70(20.88,28.54) \\
29.80(25.76,33.84) \\
46.15(43.46,48.84) \\
26.79(18.59,34.98)\end{array}$ & $\begin{array}{l}9.18 \\
9.12 \\
9.14 \\
9.15 \\
9.00 \\
9.16 \\
8.97 \\
9.06 \\
9.04 \\
9.03 \\
9.14 \\
100.00\end{array}$ \\
\hline $\begin{array}{l}\text { Respiratory tract infection } \\
\text { Habte-Gaber E. et aV1988 } \\
\text { Yallew WW. eta aV2016 } \\
\text { Tolera M.et aV2018 } \\
\text { Alemayehu T. et aV2019 } \\
\text { Gebremeskel S. et aV2018 } \\
\text { Ali S. et aV2018 } \\
\text { Subtotal (l-squared }=97.0 \%, p=0.000 \text { ) }\end{array}$ & $\underbrace{2}_{x}$ & $\begin{array}{l}5.50(3.52,7.48) \\
18.50(15.68,21.34) \\
22.20(17.57,26.83) \\
12.50(9.23,15.77) \\
19.80(16.10 .23 .50) \\
3.59(2.02 .5 .16) \\
13.51(7.29 .19 .74)\end{array}$ & $\begin{array}{l}17.11 \\
16.80 \\
15.88 \\
18.61 \\
18.40 \\
17.22 \\
100.00\end{array}$ \\
\hline $\begin{array}{l}\text { SSI and UTI } \\
\text { Sahile T. eta aV2016 } \\
\text { Ali S. et aV2018 } \\
\text { Subtotal (l-squared }=93.4 \%, p=0.000 \text { ) }\end{array}$ & ححت & $\begin{array}{l}18.60(14.68,22.54) \\
9.74(7.64,11.84) \\
14.01(5.33,22.68)\end{array}$ & $\begin{array}{l}48.16 \\
51.84 \\
100.00\end{array}$ \\
\hline $\begin{array}{l}\text { Blood stream infection } \\
\text { Sahile T. eta aV2016 } \\
\text { Yallew WW. eta aV2016 } \\
\text { Tolera M.et aV2018 } \\
\text { Alemayehu T. et aV2019 } \\
\text { Endalfer } N \text {. et aV2011 } \\
\text { Ali S. et aV2018 } \\
\text { Subtotal (l-squared }=98.6 \%, p=0.000 \text { ) } \\
\text { NOTE: Weights are from random effects analysis }\end{array}$ & $\begin{array}{l}+\infty \\
+\infty \\
x=2\end{array}$ & $\begin{array}{l}4.30(1.50,7.10) \\
14.10(11.40,16.80) \\
25.90(21.18,30.62) \\
46.60(42.58,50.62) \\
20.80(16.98 .24 .62) \\
8.20(6.18,10.22) \\
19.90(9.15,30.65)\end{array}$ & $\begin{array}{l}18.77 \\
16.78 \\
16.42 \\
18.57 \\
16.60 \\
16.86 \\
100.00\end{array}$ \\
\hline T & \multicolumn{3}{|c|}{1} \\
\hline-61.8 & \multicolumn{3}{|c|}{61.8} \\
\hline
\end{tabular}

two university hospitals in Addis Ababa Ethiopia performed hand hygiene before patient contact [40]. Evidence also showed that $35 \%$ of nurses were nonadherent to infection prevention practices in Southwest Ethiopia [41]. Besides, nearly $68 \%$ of health professionals were less satisfied with their work in the Amhara region [42]. Additionally, about $84 \%$ of nurses were morally distressed in the northwestern part of the country [43]. As a result, acquisition of HCAI from unsafe hands of unsatisfied healthcare providers augmented by less adherence to infection prevention and morally less prepared nurses might limit the quality of patient care in healthcare facilities. These may in turn increase HCAI in the country.

Healthcare workers (HCWs) disposed of that lack of hand hygiene agents and sinks in public hospitals of Addis Ababa Ethiopia [40]. The implementation of the nursing process was below half (49\%) in the northwestern part of the country [44]. Furthermore, healthcare providers, patients, and/or families are more 
Table 2 The prevalence of $\mathrm{HCAl}, 95 \% \mathrm{Cl}$ and heterogeneity estimate with a p-value for the subgroup analysis by study region, design, diagnostic method and sample size

\begin{tabular}{llll}
\hline Variables & Characteristics & Pooled prevalence (95\% Cl) & \multicolumn{1}{l}{$(\boldsymbol{p}$ value) } \\
\hline By region & Addis Ababa & $18.37 \%(13.91-22.82)$ & $98.8 \%(0.000)$ \\
& Oromia & $17.37 \%(9.19-25.56)$ & $98.5 \%(0.000)$ \\
& Amhara & $13.27 \%(9.00-17.52)$ & $99.5 \%(0.000)$ \\
& Tigray & $27.6 \%(25.37-29.83$ & - \\
& SNNPR & $21.4 \%(20.3-22.5)$ & - \\
Study design & Addis Ababa and SNNPR & $5.9 \%(4.25-7.55)$ & - \\
& Cross sectional & $18.52 \%(14.91-22.12)$ & $99.3 \%(0.000)$ \\
Diagnostic method & Cohort & $12.86 \%(7.98-17.74)$ & $98.4 \%(0.000)$ \\
Sample size & Clinical and laboratory & $18.89 \%(14.85-21.51)$ & $99.2 \%(0.000)$ \\
& Culture confirmed & $12.71 \%(6.4-19.02)$ & $99 \%(0.000)$ \\
\hline
\end{tabular}

SNNPR Southern Nations, Nationalities, and People's Region

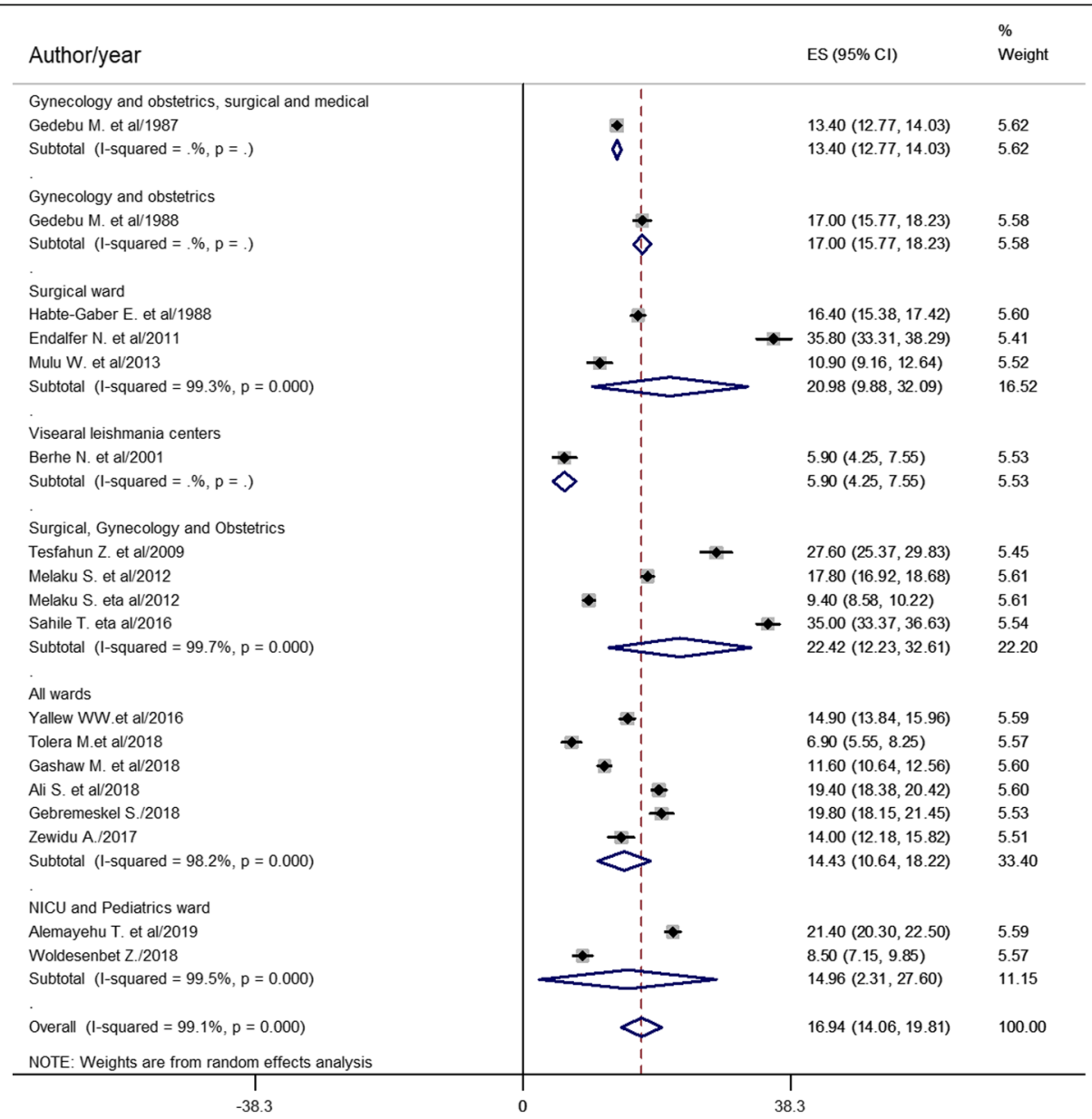

Fig. 4 Forest plot of prevalence with corresponding 95\% Cls of HCAl based on ward type 


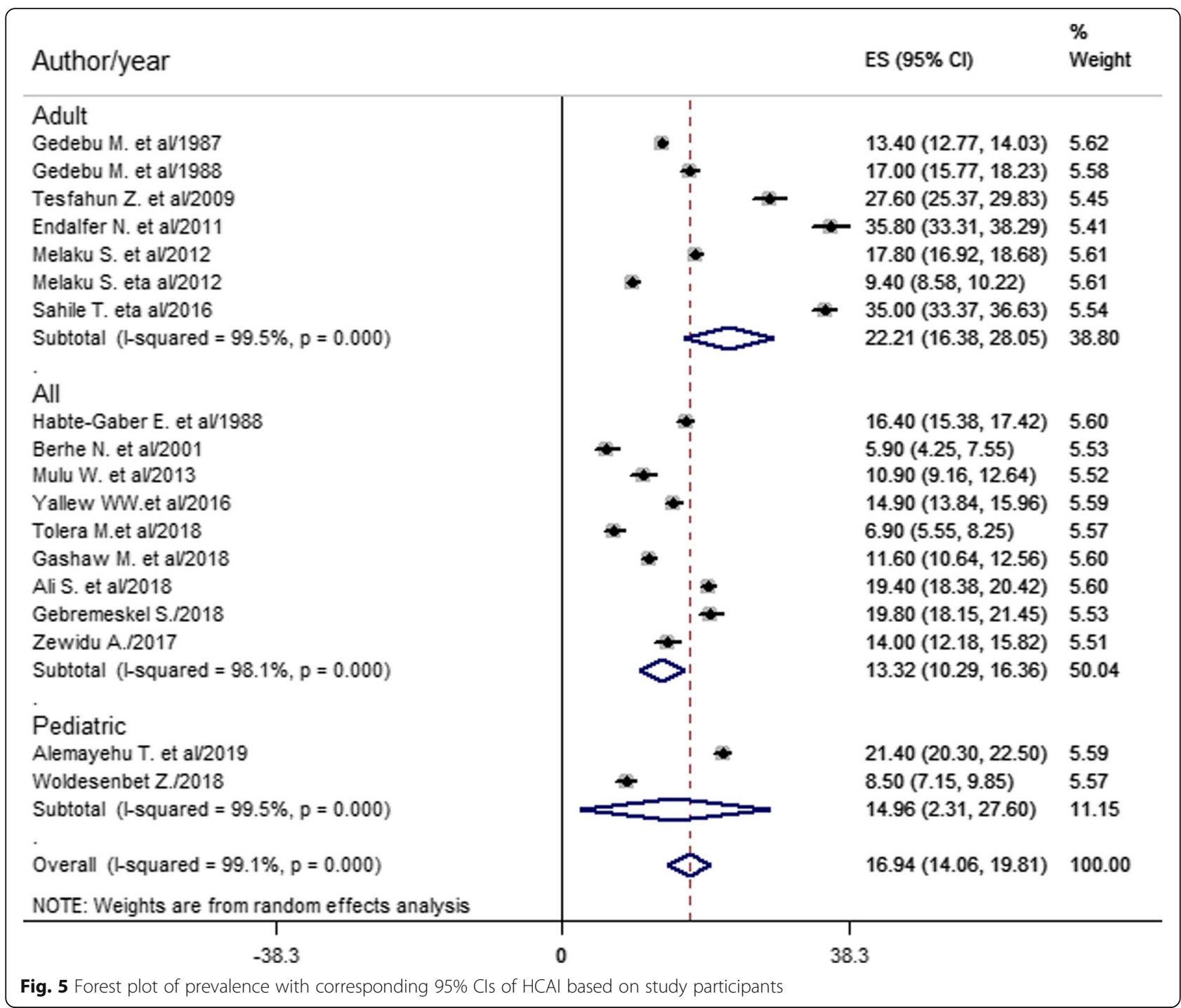

curious about the primary reason for admission or healthcare visits. Therefore, resource shortage preclude infection prevention practice, patients at risk of HCAI followed without the nursing process would not get nursing intervention, and less attention given for HCAI could justify high prevalence.

This systematic review and meta-analysis found that the most prevalent HCAI is SSI. This is greater than studies done in Morocco [8], Botswana [5], South Africa [6], and a meta-analysis done in mainland China [39]. The higher prevalence in the current finding might be due to poor surgical instrument processing, inadequate knowledge of healthcare workers (HCWs) about SSI prevention, the highest occurrence of HCAI in the surgery ward, poor SSI prevention practice by HCWs, and surgical procedure errors in Ethiopian settings. None of the HCWs in Addis Ababa Ethiopia were using biological indicators of steam (Bacillus stearothermophilus) or dry
(Bacillus subtilis) heat sterilization [45]. Knowledge of SSI prevention was found inadequate, and SSI prevention was practiced poorly at two referral hospitals in northwest Ethiopia [46]. Besides, as shown in Fig. 4 the prevalence of HCAI was the second highest in the surgery ward (20.98\%). Regarding surgical procedure errors, surgical and medical error claims in the country showed that medical error was $26.7 \%$, and the majority (72\%) of the complaints were surgical related and emerged from the operation room [47]. As a result of the above antecedents, prevalence of nosocomial SSI could be higher in the country.

A higher prevalence of SSI and an abundance of NI in the surgery ward reported in the current meta-analysis might be explained by the low density of healthcare providers in Ethiopia. The density of physicians (per 1000 population) was 0.0, 0.6, and 0.8 in Ethiopia, Morocco, and South Africa respectively while the density of nursing and midwifery personals (per 1000 population) was 
Meta-analys is estimates, given named studyis omitted
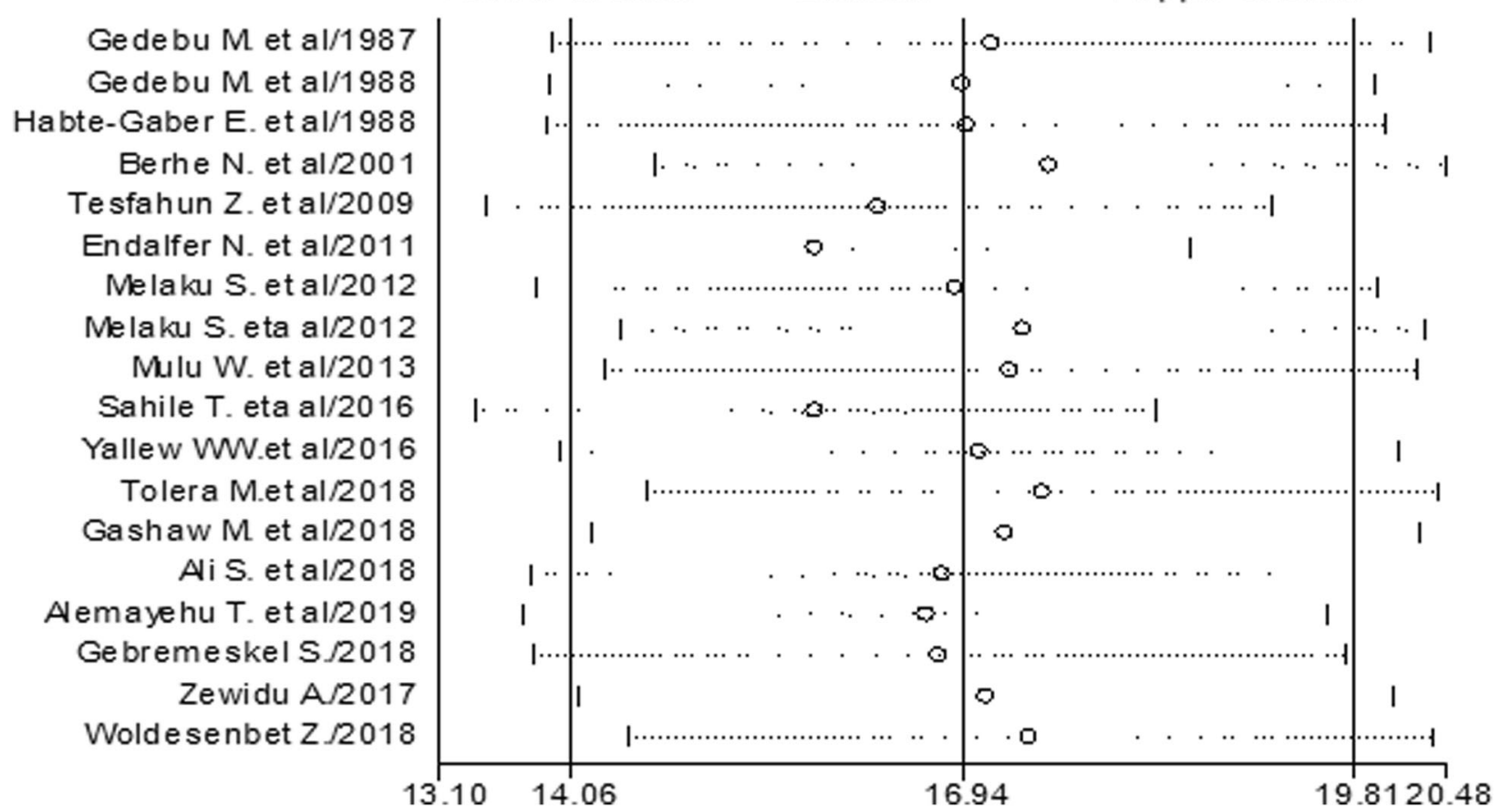

Fig. 6 The overall pooled prevalence sensitivity analysis of HCAI when the studies omitted step by step

0.3, 0.9, and 5.2 in Ethiopia, Morocco, and South Africa orderly [48]. Nurses, midwives, and physicians serving many people every day might be unable to maintain healthcare quality, so this might be another reason for higher HCAI in the surgery ward. On top of the abovementioned reasons, nurse's burnout might contribute to the high prevalence of SSI and an abundance of HCAI in the surgery ward. In the United States (US) nurse's burnout was found as a single most important associated factor for increased nosocomial UTI and SSI [49].

\section{Strength and limitation}

This systematic review and meta-analysis was the first national estimation conducted in Ethiopia. However, it may lack national representativeness because no data were found from Benishangul Gumuz, Afar, Gambella, Somalia, Dire Dawa, and Harare regions of Ethiopia.

\section{Conclusions}

In this finding, the burden of HCAI remains high. SSI was the first most common type of HCAI, followed by UTI, BSI, SSI and UTI, and RTI from highest to lowest magnitude respectively. The highest overall burden was observed in surgery, gynecology, and obstetrics ward followed by surgical ward. Hence, infection prevention and control should be strengthened and held as the priority agenda in healthcare with due emphasis for surgical site infection.

\section{Supplementary information}

Supplementary information accompanies this paper at https://doi.org/10. 1186/s41182-020-00263-2.

Additional file 1. PRISMA 2009 Checklist.

Additional file 2. Studies to estimate HCAI.

\section{Abbreviations}

AOR: Adjusted odds ratio; BSI: Blood stream infection; Cl: Confidence interval; HCAl: Healthcare-associated infections; HCWs: Healthcare workers; LMIC: Lowand middle-income country; NI: Nosocomial infection; RTI: Respiratory infection; SNNPR: Southern Nations, Nationalities, and People's Region; SDG: Sustainable Development Goal; SSTI: Skin and soft tissue infection; UTI: Urinary tract infection; WHO: World Health Organization

\section{Acknowledgements}

Not applicable

Authors' contributions

AY conceived and designed the study. AE and WA established the search strategy. All the authors read the manuscript before they have given the final approval for publication.

Funding

There is no fund received from any fund agency.

Availability of data and materials

All data generated or analyzed during this study are included in this published article.

Ethics approval and consent to participate

Not applicable because no primary data were collected.

Consent for publication

Not applicable. 


\section{Competing interests}

The authors declared that they have no competing interests.

\section{Author details}

'Department of Paediatrics and Child Health Nursing, College of Health Sciences, Debre Tabor University, Debre Tabor, Ethiopia. ${ }^{2}$ Department of Paediatrics and Child Health Nursing, School of Health Sciences, College of Medicine and Health Sciences, Bahir Dar University, Bahir Dar, Ethiopia.

Received: 20 April 2020 Accepted: 24 August 2020

Published online: 07 September 2020

\section{References}

1. What are healthcare-associated infections? [Internet]. [cited 01 Feb 2020]. Available from: https://apic.org/monthly_alerts/what-are-healthcareassociated-infections/.

2. Infections caught in the hospital [Internet]. [cited 02 Feb 2020]. Available from: https://www.healthline.com/health/hospital-acquired-nosocomialinfections.

3. Health care-associated infections FACT SHEET [Internet]. [cited 02 Feb 2020]. Available from: https://www.who.int/gpsc/country_work/gpsc_ccisc_fact_ sheet_en.pdf.

4. Mbim EN, Mboto Cl, BEJMRJI A. A review of nosocomial infections in subSaharan Africa.; 2016. p. 1-11.

5. Mpinda-Joseph P, Anand Paramadhas BD, Reyes G, Maruatona MB, Chise M, Monokwane-Thupiso BB, et al. Healthcare-associated infections including neonatal bloodstream infections in a leading tertiary hospital in Botswana. Hospital Practice. 2019;47(4):203-10.

6. Nair A, Steinberg W, Habib T, Saeed H, Raubenheimer J. Prevalence of healthcare-associated infection at a tertiary hospital in the Northern Cape Province, South Africa. S Afr Fam Pract. 2018;60(5):162-7.

7. Saleem Z, Godman B, Hassali MA, Hashmi FK, Azhar F, Rehman IU. Point prevalence surveys of health-care-associated infections: a systematic review. Pathogens Global Health. 2019;113(4):191-205.

8. Razine R, Azzouzi A, Barkat A, Khoudri I, Hassouni F, Chefchaouni AC, et al. Prevalence of hospital-acquired infections in the university medical center of Rabat, Morocco. Int Arch Med. 2012;5(1):26.

9. World Health Organization. Report on the Burden of Endemic Health CareAssociated Infection Worldwide. Geneva: WHO Document Production Services; 2011

10. Gedebou M, Habte-Gabr E, Kronvall G, Yoseph S. Hospital-acquired infections among obstetric and gynaecological patients at Tikur Anbessa Hospital, Addis Ababa. J Hospital Infect. 1988;11(1):50-9.

11. Feleke T, Eshetie S, Dagnew M, Endris M, Abebe W, Tiruneh M, et al. Multidrug-resistant bacterial isolates from patients suspected of nosocomial infections at the University of Gondar Comprehensive Specialized Hospital. Northwest Ethiopia B. 2018;11(1):602.

12. Habte-Gabr E, Gedebou M, Kronvall G. Hospital-acquired infections among surgical patients in Tikur Anbessa Hospital, Addis Ababa, Ethiopia. Am J Infect Control. 1988;16(1):7-13.

13. Allegranzi B, Storr J, Dziekan G, Leotsakos A, Donaldson L, Pittet D. The first global patient safety challenge "clean care is safer care": from launch to current progress and achievements. J Hospital Infect. 2007;65:115-23.

14. Federal Ministry of Health Ethiopia Disease Prevention and Control Department. Infection prevention guidelines for healthcare facilities in Ethiopia. Addis Ababa, Ethiopia: Federal Ministry of Health; 2004.

15. Endalafer N, Gebre-Selassie S, Kotiso B. Nosocomial bacterial infections in a tertiary hospital in Ethiopia. J Infect Prev. 2011;12(1):38-43.

16. Melaku S, Gebre-Selassie S, Damtie M, Alamrew K. Hospital acquired infections among surgical, gynaecology and obstetrics patients in Felege-Hiwot referral hospital, Bahir Dar, northwest Ethiopia. Ethiop Med J. 2012;50(2):135-44.

17. Yallew WW, Kumie A, Yehuala FM. Point prevalence of hospital-acquired infections in two teaching hospitals of Amhara region in Ethiopia. Drug Healthc Patient Saf. 2016;8:71.

18. Ali S, Birhane M, Bekele S, Kibru G, Teshager L, Yilma Y, et al. Healthcare associated infection and its risk factors among patients admitted to a tertiary hospital in Ethiopia: longitudinal study. Antimicrob Resist Infect Control. 2018;7:2.

19. Zewdu A. Health care associated infection at Adama Hospital Medical College, Adama Oromia, Ethiopia. Addis Ababa: Addis Ababa University; 2017.
20. Sahile T, Esseye S, Beyene G, Ali SJIJTDH. Post-surgical infection and antibiotic susceptibility patterns of bacteria isolated from admitted patients with signs of infection at Jimma University specialized hospital, Jimma. Ethiopia. 2016;17(4):1-12.

21. Alemayehu T, Tadesse E, Ayalew S, Nigusse B, Yeshitila B, Amsalu A, et al. High burden of nosocomial infections caused by multi-drug resistant pathogen in pediatric patients at Hawassa University Comprehensive Specialized Hospital. 2019

22. Shamseer L, Moher D, Clarke M, Ghersi D, Liberati A, Petticrew M, Shekelle P, Stewart LA. Preferred reporting items for systematic review and metaanalysis protocols (PRISMA-P) 2015: elaboration and explanation. BMJ. 2015; 349:97647.

23. Peters MD, Godfrey CM, Mclnerney P, Soares CB, Khalil H, Parker D. The Joanna Briggs Institute reviewers' manual 2015: methodology for JBI scoping reviews2015. Available from: https://www.who.int/nutrition/ publications/globaltargets2025_policybrief_lbw/en/.

24. Mulu W, Kibru G, Beyene G, Damtie H. Associated risk factors for postoperative nosocomial infections among patients admitted at Felege Hiwot Referral Hospital, Bahir Dar, Northwest Ethiopia. Clin Med Res. 2013; 2(6):140-7.

25. Gashaw M, Berhane M, Bekele S, Kibru G, Teshager L, Yilma Y, et al. Emergence of high drug resistant bacterial isolates from patients with health care associated infections at Jimma University medical center: a cross sectional study. Antimicrob Resist Infect Control. 2018;7:138.

26. Tolera M, Abate D, Dheresa M, Marami D. Bacterial Nosocomial Infections and Antimicrobial Susceptibility Pattern among Patients Admitted at Hiwot Fana Specialized University Hospital, Eastern Ethiopia. Adv Med. 2018; 2018(2127814):7. https://doi.org/10.1155/2018/2127814.

27. Woldesenbet Z. Hospital acquired infections, antimicrobial drug resistance patterns and associated risk factors among under five children attending Yekatit 12 Hospital Medical College. Addis Ababa Ethiopia: Addis Ababa University; 2018.

28. Gedebou M, Kronvall G, Habte-Gabr E, Ringertz S. The bacteriology of nosocomial infections at Tikur Anbessa Teaching Hospital, Addis Ababa. Acta Pathol Microbiol Immunol Scand B. 1987;95(6):331-6.

29. Berhe N, Hailu A, Abraham Y, Tadesse Y, Breivik K, Abebe Y. Inter-current and nosocomial infections among visceral leishmaniasis patients in Ethiopia: an observational study. Acta Trop. 2001;80(2):87-95.

30. Tesfahunegn Z, Asrat D, Woldeamanuel Y, Estifanos K. Bacteriology of surgical site and catheter related urinary tract infections among patients admitted in Mekelle Hospital, Mekelle, Tigray, Ethiopia. Ethiop Med J. 2009; 47(2):117-27.

31. Melaku S, Kibret M, Abera B, Gebre-Sellassie S. Antibiogram of nosocomial urinary tract infections in Felege Hiwot referral hospital, Ethiopia. Afr Health Sci. 2012;12(2):134-9.

32. Gebremeskel S. Management of hospital-acquired infections among hospitalized patients at Zewditu Memorial Hospital, Addis Ababa, Ethiopia: a prospective study: Addis Ababa University; 2018.

33. Rothstein HR, Sutton AJ, Borenstein M. Publication bias in meta-analysis; 2005.

34. Ioannidis JP. Interpretation of tests of heterogeneity and bias in metaanalysis. J Eval Clin Pract. 2008;14(5):951-7.

35. Borenstein M, Hedges LV, Higgins JP, Rothstein HR. A basic introduction to fixed-effect and random-effects models for meta-analysis. Res Synth Methods. 2010;1(2):97-111.

36. Yallew WW, Kumie A, Yehuala FM. Risk factors for hospital-acquired infections in teaching hospitals of Amhara regional state, Ethiopia: a matched-case control study. PLoS One. 2017;12(7):e0181145.

37. World Health Organization. Health in 2015: from MDGs, millennium development goals to SDGs, sustainable development goals: World Health Organization; 2015.

38. Allegranzi B, Kilpatrick C, Storr J, Kelley E, Park BJ, Donaldson L. Global infection prevention and control priorities 2018-22: a call for action. Lancet Glob Health. 2017;5(12):e1178-e80.

39. Wang J, Liu F, Tartari E, Huang J, Harbarth S, Pittet D, et al. The prevalence of healthcare-associated infections in mainland China: a systematic review and meta-analysis. Infect Control Hosp Epidemiol. 2018;39(6):701-9.

40. Tenna A, Stenehjem EA, Margoles L, Kacha E, Blumberg HM, Kempker RRJIC, et al. Infection control knowledge, attitudes, and practices among healthcare workers in Addis Ababa. Ethiopia. 2013;34(12):1289-96.

41. Bekele I, Yimam I, Akele GJIR. Adherence to infection prevention and factors among nurses in jimma university medical center. 2018;14(2):1-7. 
42. Temesgen K, Aycheh MW, Leshargie CTJH. Job satisfaction and associated factors among health professionals working at Western Amhara Region, Ethiopia. Health Qual Life Outcomes. 2018;16(1):65.

43. Berhie AY, Tezera ZB, Azagew AWJPR, Management B. Moral distress and its associated factors among nurses in northwest Amhara Regional State Referral Hospitals. Northwest Ethiopia. 2020;13:161.

44. Semachew A. Implementation of nursing process in clinical settings: the case of three governmental hospitals in Ethiopia, 2017. BMC research notes. 2018;11(1):173.

45. Sahiledengle B. Instrument processing knowledge and practice amongst healthcare workers in Addis Ababa, Ethiopia. Int J Infect Control. 2018;14(2):6.

46. Teshager FA, Engeda EH, Worku WZ. practice. Knowledge, practice, and associated factors towards prevention of surgical site infection among nurses working in Amhara regional state referral hospitals, Northwest Ethiopia. Surg Res Pract. 2015;2015.

47. Wamisho BL, Tiruneh MA, Teklemariam LE. Surgical and medical error claims in Ethiopia: trends observed from 125 decisions made by the Federal Ethics Committee For Health Professionals Ethics Review. Medicolegal Bioethics. 2019:9:23-31.

48. World health statistics 2018. Monitoring health for the SDGs, sustainable development goals. Geneva: World Health Organization; 2018.

49. Cimiotti JP, Aiken LH, Sloane DM, Wu ES. Nurse staffing, burnout, and health care-associated infection. Am J Infect Control. 2012;40(6):486-90.

\section{Publisher's Note}

Springer Nature remains neutral with regard to jurisdictional claims in published maps and institutional affiliations.

Ready to submit your research? Choose BMC and benefit from:

- fast, convenient online submission

- thorough peer review by experienced researchers in your field

- rapid publication on acceptance

- support for research data, including large and complex data types

- gold Open Access which fosters wider collaboration and increased citations

- maximum visibility for your research: over $100 \mathrm{M}$ website views per year

At BMC, research is always in progress.

Learn more biomedcentral.com/submissions 